\title{
Mapping Academic Publishing: Locating Enclaves of Development Knowledge
}

\author{
Saman Goudarzi and Tasneem Mewa
}

\section{Introduction}

1 Academic citations and bibliographic data often indicate publication biases, namely geopolitical biases, in journal articles. While these indicators are quantifiable, audiences can benefit from mapped data visualizations. The poster presented at the ELPUB 2018 Conference demonstrates the early outputs of a larger project that aims to identify and visualize unequal trends of publication in the field of international development. The aim of this project is twofold: to determine the institutional affiliation of individuals publishing in prominent development journals and working to provide an accessible means to visualize the representational disparity between academics affiliated with institutions in the Global North and South. The poster shows the results thus far of this project, depicting the distribution of authorship for the influential development journals, the Journal of Peasant Studies and Third World Quarterly between 2005 and 2015.

\section{Methods}

2 The maps draw from affiliation data collected both through the Scopus database and email interviews for published articles in the study journals. The Scopus database was chosen because it possessed the most complete bibliographic information for these journals while offering an accessible interface through which to collect this information. In fact, the most complete bibliographic information existed for the study years, 20052015; years which also mark significant changes in journals ownership structures and in the success of these journals according to metrics such as impact factors (see graph below). Once the affiliated institutions were determined, they were geocoded using 
Google's geocoding API to generate spatial data. This data was then joined with the aggregated affiliation data to create a proportional symbol map where the size of the point-symbol represents the quantity of articles published by an institution throughout the study years. While the data presented in the poster depicts contemporary publishing patterns for the study journals, it is also important to note the historical context of these journals as to gain insight into the changing publishing landscape underlying these contemporary trends.

Thomson Reuters Journal Impact Factor of the Study Journals, 1997-2015

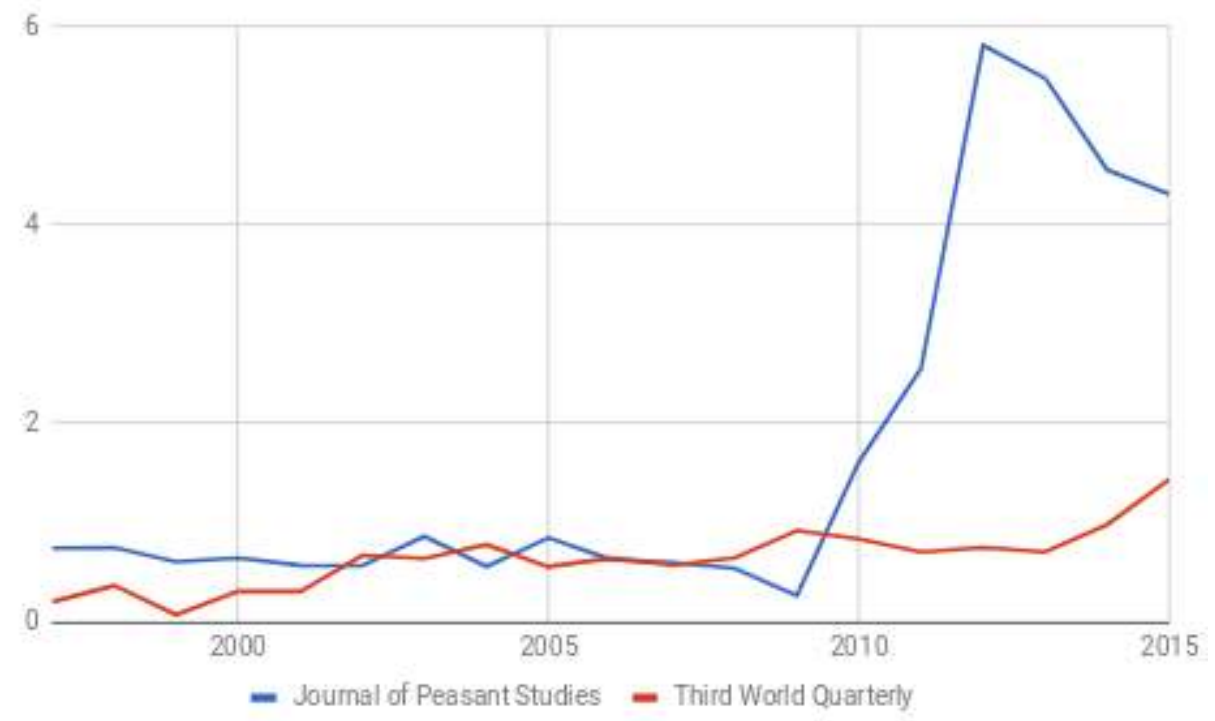

Data Source: Thomson Reuter's Incites Journal Citation Reports

\section{Historical Context of Journals}

The Journal of Peasant Studies and Third World Quarterly were helmed by academics in England as smaller scaled publications. Presently, following a series of mergers and acquisitions, both journals are owned by the international company Taylor \& Francis. During the late 70s to early 80s, Third World Quarterly was focused on garnering attention for the socioeconomic realities in the Global South ${ }^{1}$ and on third world media outlets. During the early 1990s, Carfax Publishing purchases Third World Quarterly. In 1997, Routledge purchases Carfax Publishing, and the former is bought by Taylor \& Francis the following year (Steele, 2014).

Similarly, the Journal of Peasant Studies started publishing journals in 1973 with the British publisher Frank Cass \& Co. In 2003, Taylor \& Francis acquired the publishing company (Steel, 2014). Financial returns remain a priority as the publishing process becomes more concentrated (Chen and Posada, 2018). In part, this is made evident in press releases, where shareholder benefits are communicated to be the primary concern (in lieu of journal goals, objectives, and knowledge creation) (Factiva, 2018). 


\section{Findings}

Journal of Peasant Studies-Quantities of Articles Published from Affiliated Institutions

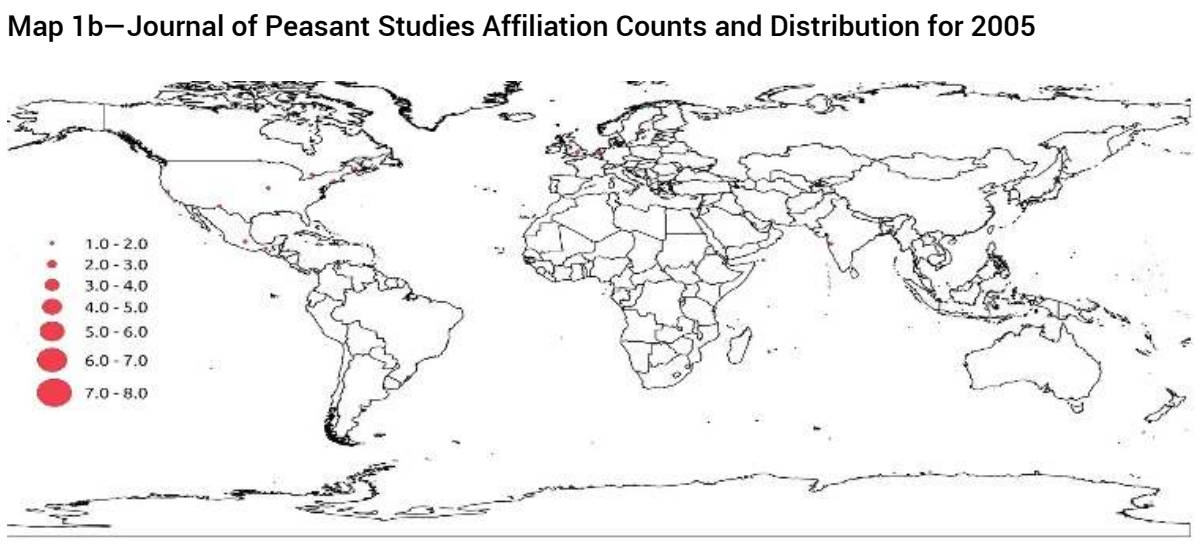

Map 2b-Journal of Peasant Studies Counts and Distribution for 2012

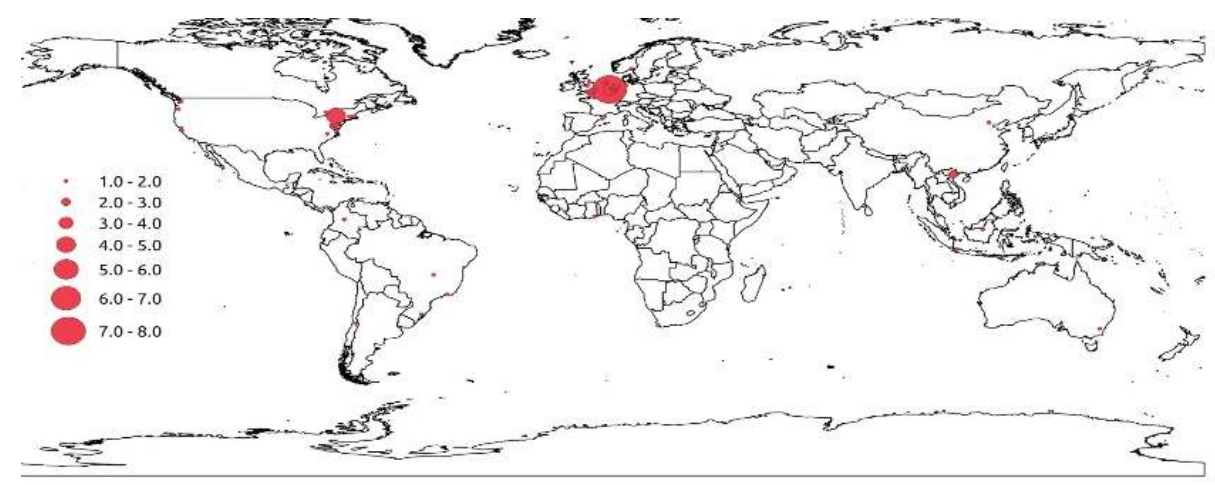

Map 3b-Journal of Peasant Studies Counts and Distribution for 2015

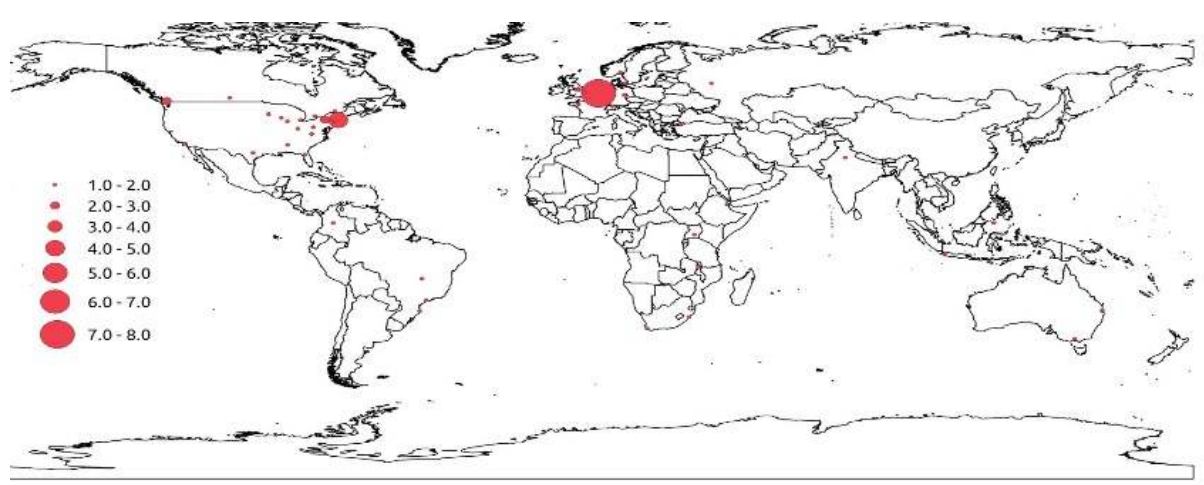


Map 4b-Journal of Peasant Studies Institutional Country Total Counts

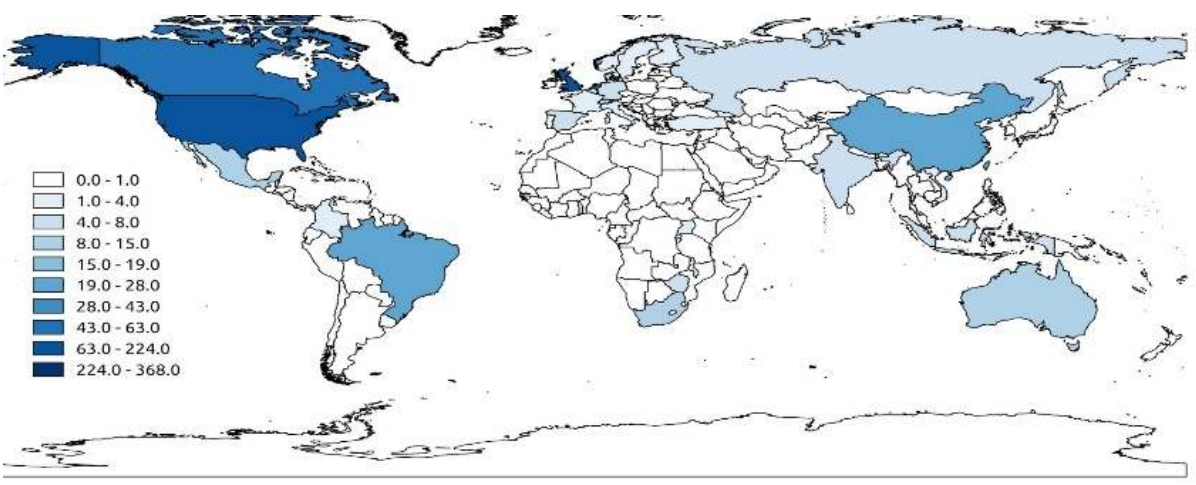

Third World Quarterly-Quantities of Articles Published from Affiliated Institutions

Map 1a-Third World Quarterly Affiliation Counts and Distribution for 2005

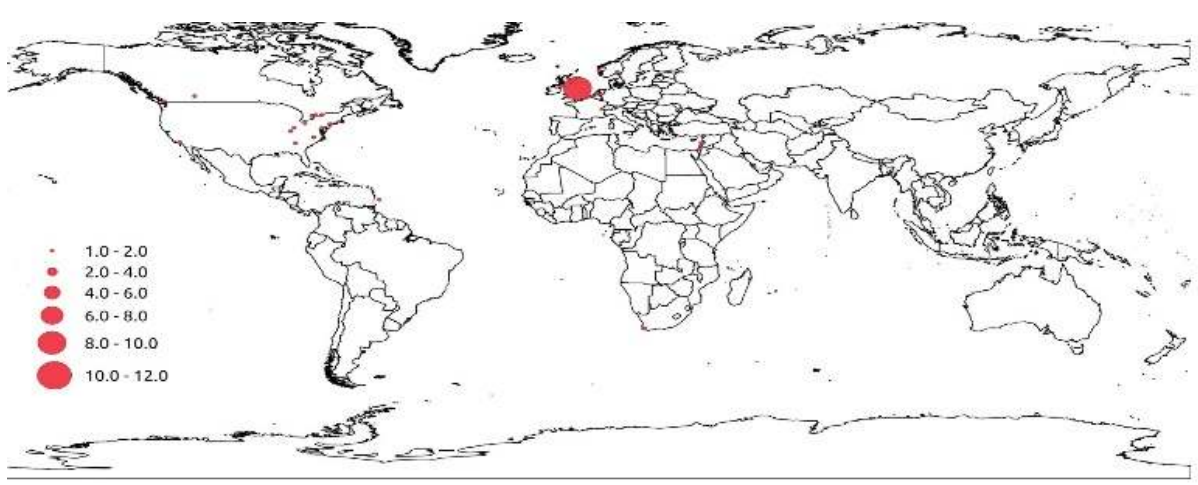

Map 2a-Third World Quarterly Affiliation Counts and Distribution for 2012

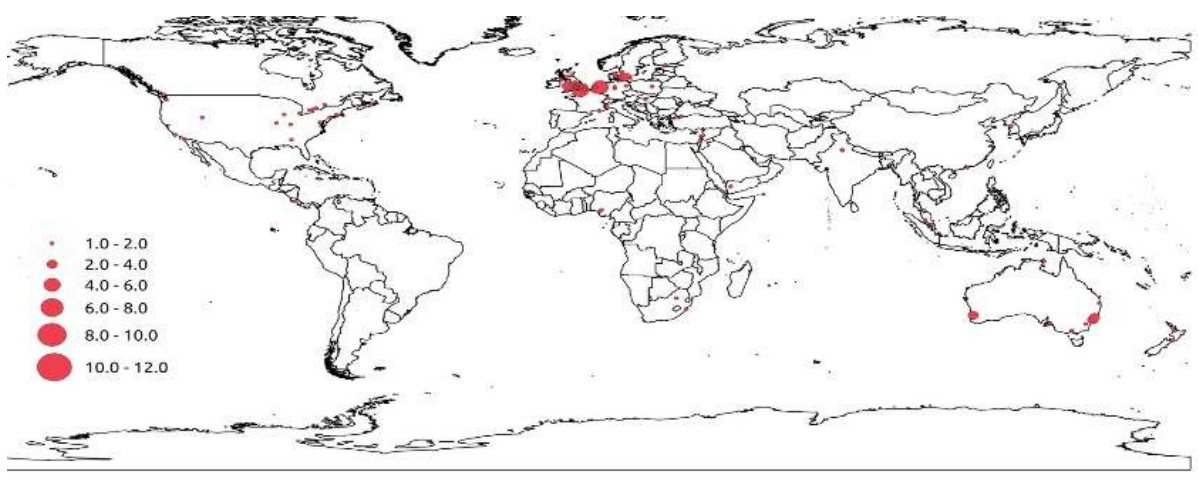


Map 3a-Third World Quarterly Affiliation Counts and Distribution for 2015

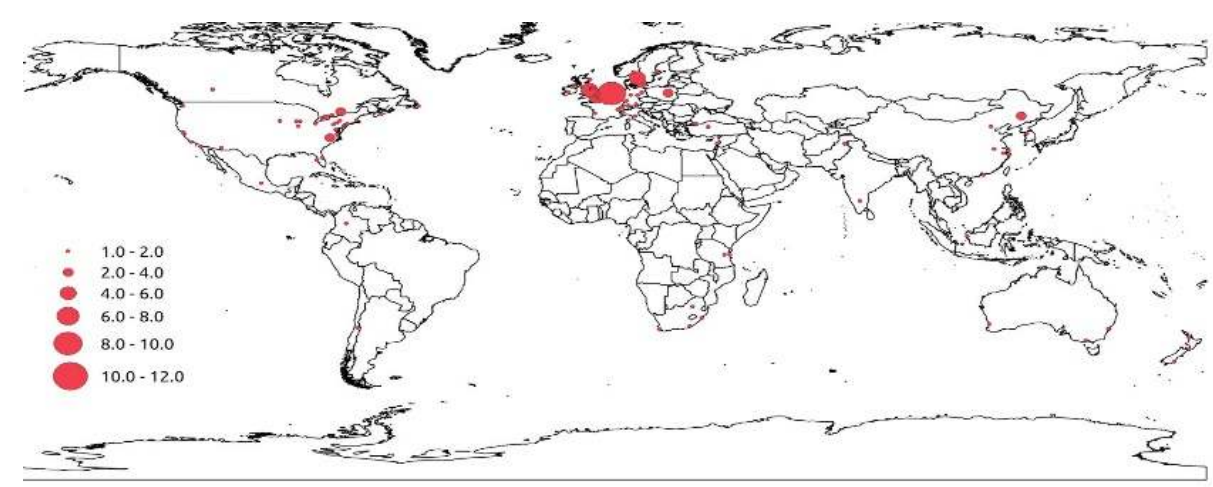

Map 4a-Third World Quarterly Institutional Country Total Counts

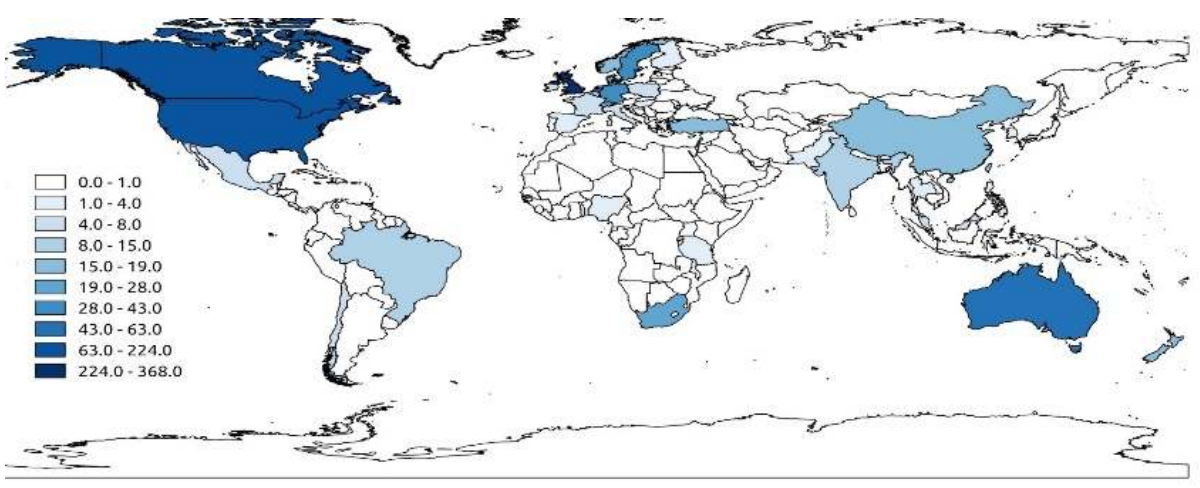

5 We analyze the geographical distribution of institutional affiliation throughout the study years. For this manuscript, we included visualizations of this data for 2005 and 2015-the start and end of our study years-as well as the years when the journal achieved the highest impact factor (Third World Quarterly achieves this in 2015 but a 2012 map here is included for comparative purposes).

6 The maps for the study journals above suggest geographic bias in academic publication with Global South institutions being poorly represented in development studies journals published in the Global North. Throughout the study period, for example, only $22 \%$ of affiliated institutions are located within the Global South for the Journal of Peasant Studies. Third World Quarterly fares much worse, with only 13\% of affiliated institutions located in the Global South.

7 It should be noted that the number of articles being produced by both journals increases steadily throughout the study years. This trend is accompanied by the increase in authors contributing to these journals. The Journal of Peasant Studies sees a 359 percent increase from 2005 to 2015 while Third World Quarterly sees an increase of 154 percent. The Scopus database maintains 18 articles from the Journal of Peasant Studies for 2005 and 51 for 2015. Third World Quarterly, sees an increase from 59 articles to 125 for the same years. Interestingly, this increase in the number of articles being produced has different implications for geographic institutional diversity between the study journals. While data for Third World Quarterly demonstrates a general positive trend in Global South institutions represented (representation doubling from about 10 percent to 20 percent between 2005 and 2015), data for Journal of Peasant Studies suggests a general negative 
trend, with Global South institutions represented less (representation drops from 30 percent to 21 percent).

\section{Discussion and Future Work}

8 These maps demonstrate changes in the quantity of articles being published throughout the study period. Evidently, publishing companies associated with the study journals are scaling up in terms of their products. In the case of the Journal of Peasant Studies, these trends are accompanied by a scaling down in terms of the geographic diversity of included institutions. Beyond a geographical analysis, further insights can be gained through analysing the financial flows underlying the illustrated geographic disparities.

9 The unequal patterns of representation have serious implications for development theory and practice. The knowledge disseminated in these journals is often produced with the intention of informing development policy and practice. As such, it has implications for the types of projects that get pursued in the name of development. This is especially significant considering that most of this knowledge can be linked back to a concentrated group of institutions, particularly those situated in the Global North.

Increasing visibility through mapping and visualizing technologies is only the first step to highlighting an uneven chain of academic knowledge production and understanding the unequal structural forces at play. Revealing geographical biases will hopefully inspire a more critical lens to the academic information we consume. Furthermore, it will highlight alternative approaches to knowledge production and dissemination that would promote increased variety of in depth contextual analysis. Hopefully, this data can provide one of many perspectives necessary to understanding how academic publishing can operate without engendering representational inequalities; all the while being cognizant of how buzzwords such as "open access" can be manipulated to conform to similar logics that currently drive the publishing landscape.

11 After collecting and visualizing the relevant empirical data, we can begin to correlate it with changes in the quantity of articles being published to changes in ownership, distribution of academic development knowledge, and impact factor. As previously mentioned, the Journal of Peasant Studies was purchased by Taylor \& Francis in 2003. Following this purchase, the journal's Thomson Reuters Impact Factor saw a 40 percent increase (Thomson Reuters, 2016) (see Thompson Reuters Journal Impact Factor graph above). It is important to note that impact factors embody social and economic value and are perhaps indicative of the multinational dominance of few publishing companies and how their actions and practices contribute to whose knowledge is ranked and valued.

12 A journal's impact factor for a particular year is calculated using citations of the journal's published articles from the two preceding years (Thomson Reuters, 2018). Interestingly, there seems to be a correlation between Global South representation and Impact Factor; relatively greater Global South institutional representation was observed when impact factor was at its highest. However, larger sample sizes and further inquiry into these trends are needed to establish any type of relationship.

13 Alongside quantitative analysis, events such as the act of publishing papers in favour of colonialism (as Third World Quarterly did in September of 2017), highlight the importance of clickbait and the devaluing of editing procedures and expertise. Further research questions could interrogate the editorial board membership, and the impacts of 
multinational dominance on academic careers. These research areas may highlight the necessary pathways and values that would enable instances such as the release of extremely controversial articles. Beyond Scopus and other databases, interviews with industry insiders would prove useful in examining these questions.

Recent years have seen greater attention being paid to issues surrounding disparities in representation within the academic publishing sphere (Cummings \& Hoebink, 2016). This project and its further inquiries hope to contribute to this growing area of research.

\section{BIBLIOGRAPHY}

\section{References}

Chen, G., \& Posada, A. (2018). "Inequality in Knowledge Production: The Integration of Academic Infrastructure by Big Publishers”. ELPUB 2018 Conference.

Cummings, S., \& Hoebink, P. (2016). "Representation of academics from developing countries as authors and editorial board members in scientific journals: Does this matter to the field of development studies?" The European Journal of Development Research, 1-15. https:// doi.org/10.1057/s41287-016-0002-2

Factiva. (1998). "Taylor \& Francis Gp Re Acqn., Placing \& Open Offer." Regulatory News Service (RNS).

Steele, R. (2014). “About Taylor \& Francis, the Academic Division of Informa plc," Editors' Bulletin, 9:1, 13-18, https://doi.org/10.1080/17521742.2013.870718

Thomson Reuters. (2016). “InCites Journal Citation Reports.” Web of Science. Retrieved May 10, 2016 from: https://jcr.incites.thomsonreuters.com/

Thomson Reuters. (2018). “Journal Impact Factor.” InCites. Retreived May 20, 2016 from: http:// ipscience-help.thomsonreuters.com/inCites2Live/indicatorsGroup/aboutHandbook/ usingCitationIndicatorsWisely/jif.html

\section{NOTES}

1. These power dynamics can be complicated beyond the dichotomy of North-South institutions. Considering the importance of an intersectional lens, gender, race, ethnicity, and other identity markers all have a role to play in nuancing this binary. However, this data is difficult largely unavailable. Additionally, defining a global South scholar is arbitrary (would this be according to where the scholar studied, was born, was raised, currently lives?). Moreover, within the aims of this project, although there are variations in power between individual scholars, it is ultimately the level of the institution where most power is afforded. 


\section{ABSTRACTS}

With the intention of highlighting enclaves [in this context, the term enclave simply refers to exclusive concentrations of academic development knowledge; ultimately leading to narrow frames for development practice and policy] in academic knowledge production, this poster portrays geographic variations in the institutions represented by articles published in the Journal of Peasant Studies and Third World Quarterly from 2005-2015 via proportional symbol maps. Empirical data was collected via the Scopus database. Visualizing empirical bibliographic data shows higher percentages of academic publications from institutions located in the Global North. While the chain of academic publication and dissemination is extensive, this map focuses solely on the quantity of academic articles published. These representational inequalities can be paralleled in academia and other forms of exchange and work towards deconstructing perpetual structural inequalities.

\section{INDEX}

Keywords: Geography, Data Visualization, Academic Publishing Representation, International Development

\section{AUTHORS}

\section{SAMAN GOUDARZI}

University of Toronto, Scarborough, Canada

saman.goudarzi@mail.utoronto.ca

(corresponding author)

\section{TASNEEM MEWA}

University of Toronto, Scarborough, Canada

tasneem.mewa@mail.utoronto.ca

(corresponding author) 